\title{
EL DERECHO DE LAS LENGUAS \\ (a propósito de las lenguas de la Unión Europea)
}

JOSÉ ASENSI SABATER

\begin{abstract}
«Al principio cuando se empezó a construir la Torre de Babel todo fue bastante bien (...) a la segunda o tercera generación, se conoció la inanidad de construir una torre que tocara el cielo, pero se habían creado demasiados lazos en ese momento para que se abandonase la ciudad».
\end{abstract}

\section{EL CONFLICTO DE LAS LENGUAS Y LOS DERECHOS FUNDA- MENTALES}

El estado de los derechos es hoy más que nunca un tema relevante de discusión, al menos en Europa, donde la irreversibilidad y las dudas respecto de la transformación de la estructura del Estado marcan un punto álgido, probablemente decisivo, que no puede esperar. Frente a la extensión de los derechos, la igualación de textos, la copia, en el mejor sentido, de las producciones jurisprudenciales, frente a la emergencia de un «sistema de derechos» más o menos común en la Unión Europea, se alza el problema de las lenguas, de los idiomas oficiales que habían circunscrito históricamente tales derechos al marco estatal. A partir de este hecho, de esta disociación tan conocida, ¿no es algo más que una coincidencia que muchos de los análisis que deploran la inexistencia de una tabla de derechos de la Unión Europea omitan una referencia directa al problema de las lenguas?, y sin embargo, ¿no es natural que la pretensión de construir un Derecho Público europeo haya de implicar inevitablemente un contenido dogmático (un ius publicum como Corpus iuris civitatis), es decir, una definición de los derechos ciudadanos que pasa por establecer los términos linguísticos de tal definición? Pero las dificultades empiezan aquí, precisamente, y son más recientes de lo que parece, pues mientras la $\mathrm{CE}$, tiempo atrás, funcionó primordialmente como un espacio económico no afloró el problema de las lenguas en la medida en que amenaza ahora, cuando se ha producido una hipertrofia de la producción jurídica en el ámbito comunitario y cuando aquélla requiere, para su articulación, de la implementación de un espacio político (la ciudadanía europea, los derechos sociales, la legitimación institucional etc.).

Apenas nombrado, como corresponde a un tema que por muchos conceptos ha sido tabú, el conflicto de la lenguas, y en primer lugar entre las lenguas oficiales, no puede ser ya apaciguado mediante las reglas que hasta ahora han regido esta 
materia ${ }^{1}$. Algunos debates, diversas resoluciones del Parlamento europeo y tomas de posición de los Gobiernos, anticipan una problemática que no ha hecho más que empezar de un modo más o menos explosivo², aunque se perfila como uno de los escollos más peligrosos ante el proyectado proceso de ampliación de la Unión a otros Estados y otras lenguas. Las cuestiones implicadas aquí son muchas y de variado cariz; por citar una que, lógicamente, no podré abordar en el contexto de este trabajo, está el desafío, inquietante y radicalmente nuevo en sus dimensiones, de un sistema de Derecho cuyo proceso de producción jurídica no se expresa en una lengua dominante, revestida de una autoridad suprema, desde la que fuera posible predicar una interpretación o una traducción sino que, en el ámbito de la UE, ese sistema jurídico se ha de construir sobre la base de un estatuto de igualdad formal entre las lenguas oficiales de los Estados, si bien a duras penas puede ser éste aplicado ${ }^{3}$ ¿ ¿No cabe ver aquí un problema que afecta a la manera en que el Derecho se produce transformándose su forma de alumbramiento habitual? No es éste desde luego un problema marginal, teóricamente superable mediante la

1 Sobre el régimen lingüístico de la Unión, vide. Mercè Corretja i Torrens, «La unión europea y el multilinguismo», en Noticias de la Unión Europea, ${ }^{\circ}$ 127-28, agosto-septiembre, 1995.

2 Vide, Diario Oficial de las Comunidades Europeas, $\mathrm{n}^{\circ} \mathrm{C} 179 / 4$ (13.7.95) sobre lenguas oficiales y lenguas de trabajo de la Unión Europea; $n^{\circ}$ C $30 / 56$ (6.2.95). Debates del Parlamento Europeo, $n^{\circ}$ 4-456/71 (17.1.95). Vide. Parlamento Europeo (Documentos de Sesión, A3-0189/92 (21.5.92) sobre la articulación y estrategia de la Unión Europea con vistas a su ampliación y a la creación de un orden global a escala europea. En su apartado 24, en lo que respecta a la utilización de las lenguas en el marco de la Unión europea ampliada, se afirma que «el respeto de la diversidad cultural y de la seguridad jurídica hacen indispensable que las lenguas de los países de la Unión Europea sean lenguas oficiales de la Unión Europea. Vide: resoluciones del Parlamento europeo de 8.11.82 ( $\mathrm{n}^{\circ} \mathrm{C}$ 292/96) sobre el multilinguismo de la Comunidad Europea. Debate del Parlamento Europeo (17.1.95), $\mathrm{n}^{\circ}$ 4-456/71: En en el contexto de este debate, la Presidencia del Consejo reitera la posición tradicional: que el régimen linguístico de la Unión, establecido en el artículo 217 del Tratado continúa en vigor y que el problema se planteará «cuando tengamos, no ya once lenguas como ahora, sino veinte, veinticinco y treinta lenguas, como consecuencia de la ampliación a los países de la Europa central y oriental... Ese día probablemente haya que planterase el problema de la distinción entre lengua oficial y lengua de trabajo» (M. Lamassoure, Presidente en funciones del Consejo). Sin que sea aquí posible desarrollar este aspecto, es claro que, en la actualidad, la distinción entre lengua oficial y lengua de trabajo atraviesa una profunda crisis: el régimen linguístico actual es el resultado y fruto de la suma de visiones nacionalistas de cada Estado en el momento de negociar su admisión en la CE. (Vide: M. Reniu, «Un nou model lingüistic per a Europa», en Revista de Llengua i Dret, 21, julio 1994.

3 Con frecuencia, cuando se emplean los términos de «traducción», «versión», etc., pareciera darse por sentado que toda traducción de normas tiene como misión restituir en la lengua vertida la autoridad del texto traducido. El origen de la Comunidad Europea y las diferentes coyunturas en que se ponen el marcha las instituciones, delatan numerosas disfunciones y contradicciones «menores» en la aplicación de la cooficialidad de lenguas, su traducción y validación. Como se sabe, el Tratado de la CECA, por ejemplo, se redactó sólo en francés, por lo que éste es el único texto auténtico y al que se debe someterse toda duda interpretativa. Los Tratados CE y CEEA tienen cuatro versiones «auténticas» (alemán, francés, italiano y holandés). En el ámbito judicial y como reminiscencia de la lengua «franca» que inicialmente fue el francés, en el Tribunal de Justicia comunitario, los jueces deliberan en este idioma sin valerse de intérprete. etc. Vide. ISAAC, Guy, Manual de Derecho Comunitario, Ariel, 1992. 
apelación a un perfeccionamiento de las técnicas de traducción (y, desde luego, un aumento de los recursos económicos), puesto que afecta, precisamente, no a la mera traductibilidad (que en sí misma encierra innumerables problemas) sino a la génesis misma de las normas, a su proceso de producción, a lo que llamamos comúnmente las Fuentes del Derecho.

Vamos, pues, a centrar la atención en algunos planteamientos que se derivan de esta problemática más o menos oculta de las lenguas (y del derecho que éstas reclaman) y que, urgidos por la inminencia o por la necesidad de avanzar hacia ese Derecho Público europeo, han tomado el camino más corto (aunque no por ello necesariamente el más acertado) y más tentador, esto es, el de la afirmación de que existe una «lengua», la del Derecho mismo, una lengua técnico-jurídica independiente de las lenguas nacionales, en la que todos los derechos podrían expresarse, ejercerse, como la condición básica para poder construir un Derecho Público europeo dotado de los principios de seguridad y certeza ${ }^{4}$. Tal es, o a esta dirección se abre, la tesis de E. García de Enterría expuesta recientemente en su libro «La lengua de los derechos» ${ }^{5}$. Se me permitirá referirme con alguna extensión a este trabajo, con el fin de perfilar, a partir de él, algunos puntos sobre los que considero deseable llegar a una mayor clarificación, sobre todo cuando surge, en la sede misma de cada una de las instituciones de la Unión Europea, un problema de lenguas y de competencias y, también, un problema de derechos y de autoridad. ¿Cómo abordar esta cuestión que ya no espera, cómo enfocar u orientar

4 Esta es, naturalmente, la perspectiva más general desde la que se aborda habitualmente el análisis del incipiente Derecho Público europeo y difícilmente puede ser de otro modo. Recientes trabajos de autores españoles reflexionan sobre la incidencia en él de la problemática de las lenguas: vide. Francisco González Navarro, «Multilinguismo y unidades jurídicas en Derecho Comunitario Europeo», paradigmático en su pretensión de desviar la problemáica linguística, de la que parte, en una vaga solución sistémica o, como el autor la denomina, estructural: «... Tenemos que llegar a entendernos en una lengua que no sólo es nueva para nosostros sino que se está haciendo. No se trata de una lengua que debamos «inventar». Esto sería un artificio indeseable por empobrecedor. Sino de una lengua que está naciendo entre nosotros: la nueva lengua jurídica comunitaria, cuyos vagidos irán convirtiéndose en sonidos articulados perfectamente inteligibles», etc. - $\mathrm{Y}$ añade:... «el camino para llegar a ese conocimiento existe: se llama análisis estructural... que permita la determinación precisa de las unidades jurídicas en los distintos ordenamientos nacionales integrados en el comunitario...» (págs. 56-57). Una perspectiva similar puede verse en el trabajo de Ignacio Granado Hijelmo, «Constitución europea y jurisprudencia de sistemas» (REE-45, $\mathrm{n}^{\circ}$ 9, 1995); tras exponer las dificultades que se presentan para construir un Derecho común europeo que «si bien puede y debe recabarse de aquéllos orígenes latinos, no puede que la tradición jurídica anglosajona conduce a postulados no siempre parangonables con la tradición continental hispano-francesa e italiana, sin olvidar que también deberán ser integrados sistemas jurídicos de tradición germánica, hanseática cuando no eslava, báltica, danubiana o escandinava» llama a superar tales problemas- ya que los «juristas estamos llamados a una especial colaboración porque, en definitiva, somos los principales responsables de buscar esperanzas jurídicas para un tiempo de crisis» y para ello hay que acudir —según el autor-a las soluciones que aportan la Jurisprudencia de Sistemas, la teoria de las competencias concéntricas y la doctrina del neofederalismo». (págs. 39-56)

5 Eduardo García de Enterría, «La lengua de los derechos. La formación del Derecho Público europeo tras la Revolución Francesa». Alianza Universidad, Madrid 1994. 
ese tráfico de traducciones, de interpretaciones y de textos autentificables que, no obstante, requieren autoridad? Y sobre todo, ¿porqué ello habría de constituir un problema? ¿Se trata solamente de una competencia linguística que ha de ser afinada y reservada como competencia técnica a la labor de los juristas o está en juego un problema que afecta de lleno a los derechos fundamentales de los ciudadanos?

\section{LA LENGUA DE LOS DERECHOS}

«La lengua de los derechos» es el título sugerente, ambigüo también a primera vista, bajo el que Eduardo García de Enterría (en adelante EGE) pronunció su discurso de ingreso en la Real Academia Española de la Lengua. Rehecho después, aunque «queda algún resto de ese origen», se publicó en forma de libro con el subtítulo «la formación del Derecho Público europeo tras la Revolución Francesa» (1994). Ensayo brillante, ilumina una escena algo confusa, la de los derechos, los «derechos ciudadanos» en primer término y su origen revolucionario.

La exposición de EGE es muy directa y guarda más de una relación con la problemática actualidad de los derechos: para tratar de los derechos, para tratar con ellos, viene a decir EGE, es preciso entenderse, hablar en $s u$ lengua, ya que la tienen o la deben tener; una lengua que debe poder clarificar sus significados, permitir un tratamiento sistemático-jurídico de los derechos, preveer y controlar sus previsibles dispersiones, garantizar su fuerza (la «enforced»o coactividad implicada en todo derecho), es decir, también su aplicabilidad y su estatuto; una lengua capaz de expresar por ello un sentido unitario, de revelar, en fin, el sistema al que todos los derechos pertenecerían y que nos permitiría, por ejemplo, traducir la razón que los domina y que justifica su pertenencia a tal sistema: ¿no debe ser ésta la primera (si no la principal) labor del jurista, la responsabilidad misma que consiste en poner en juego su competencia jurídico-técnico-linguística para precisar el alcance de los derechos y traer a éstos de la esfera de la razón y la justicia a su posibilidad concreta de realización en un orden jurídico que no sería tal si no los determinara con el máximo rigor y precisión? Pero ello - y aquí residiría tal vez el arranque de la cuestión implicada en la hipótesis de EGE - ¿no precisa y presupone la inteligibilidad de «la» lengua, del derecho mismo, y sobre todo, no sería precisa la apelación a una «archilengua» que permitiera la traducibilidad entre ellos, de los distintos Derechos, puesto que de lenguas se trata? ¿Qué riesgos entrañarían, sin embargo, tales operaciones?

Como no podría ser de otro modo, EGE no ignora que una competencia linguística, involucrada inexorablemente en la función del jurista, citando a K.M. Baker (Inventing the French Revolution, 1990), no podría evitar ser una forma de autoridad, una cuestión de «autoridad política» (pág. 41): La lengua de los derechos es, como siempre ha sido, una lengua del poder y también la expresión de un 
poder sobre las lenguas en que aquéllos se expresan; funciona entonces como el presupuesto mismo de la autoridad (gewalt) ${ }^{6}$ y del lenguaje por el que se legitima, señalando de paso, la doble problemática del origen de esa lengua y de esa autoridad. Para EGE, tal lengua tiene un origen preciso: irrumpe con la Gran Revolución francesa, prestando incluso a ésta su propio nombre. La Revolución supuso un corte o un desgarro repentino, (un «tajo», señala gráficamente EGE) y en él, en ese momento suspendido e indecidible de la fundación de un nuevo orden, se marcaría ya, en ese juego de conceptos que maneja EGE, la precedencia entre un «logos», la razón o el lenguaje, y la Revolución como «hecho», como realidad irruptiva, como irrupción política ${ }^{7}$; como trataremos de hacer más adelante, habría que determinar las implicaciones necesarias de estos dos órdenes representados como separados en el momento de su eclosión misma ${ }^{8}$.

En la segunda parte del libro de EGE se constata ese giro que va desde la consideración de la lengua como el soporte de los nuevos términos y los nuevos significados revolucionarios, al discurso como lenguaje trabado y significativo en su conjunto; EGE lo titula «la lengua de los derechos como lengua técnica de ordenación de la sociedad política» (La formación del derecho público postrevolucionario, subtitula EGE). Se produce así un deslizacimiento de la formulación principal, «la lengua de los derechos» —en el cual, el término «lengua» cobraría ahora un sentido metafórico- a lo que sería propiamente el discurso de

6 Gewalt puede significar violencia; pero también significa poder legítimo, autoridad, fuerza pública. Gesetzgebende puede traducirse como poder legislativo; Geisetzgebende Gewalt, es el poder espiritual de la Iglesia. Staatsgewalt, es el poder o la autoridad del Estado. Gewalt podría también traducirse por la «autoridad justificada».

7 Pese al esplendor de la lengua, del francés, en la época de la Revolución, habría que traer aquí la violencia de la imposición como lengua del Estado. Michel Certeau y Jacques Revel (Une politique de la langue. La révolution française et les patois: L'enquête de Gregoire, Paris, Gallimard, 1975) señala cómo la resistencia contra la Revolución es interpretada a menudo por los revolucionarios como el acto de una fuerza y de una forma linguística. Brunot, por su parte, cita (t. IX, $1^{\mathrm{a}}$ parte) cómo Barère escribe a la Convención en un informe del Comité de Salud Pública: «... el federalismo y la superstición hablan bajo bretón; la emigración y el odio a la República hablan alemán; la contrarrevolución habla italiano y el fanatismo habla el vasco». El Decreto del 2 de Thermidor prohibe en todo acto, incluso en los de carácter privado, todo otro idioma que no sea el francés, etc. (JD, La Filosofía en su Lengua Nacional, 49).

8 Así, unas veces, EGE resalta que «no es extraño... que la Revolución Francesa tuviera efectos inmediatos sobre la lengua»; otras (pp. 26) citando un texto de $\mathrm{Ph}$. Roger, subraya que la Revolución era, «ya» desde sus orígenes, una «guerra de palabras, una genuína logomaquia» ( $\mathrm{Ph}$. Roger, 1958), o bien que la Revolución francesa... «es» una revolución lingüística, la única revolución lingüística hasta el presente en la historia del francés nacional (R. Balibar, 1985)», una «lengua del poder (que) va a intentar convertirse inmediatamente en la lengua del Derecho» (pág. 29). ¿A qué se deben estas vacilaciones, si es que lo son? Añade EGE: «Así las palabras juegan un papel decisivo a lo largo de todo el proceso revolucionario, prestándole un dinamismo peculiar. Se desarrollan por unos y por otros especiales estrategias del lenguaje...hablar va a ser combatir, en el sentido de actuar, y los actos del lenguaje van a participar, y no en último término precisamente, de una agonística general. Quien gana la batalla de las palabras puede ganar normalmente la posición política dominante, puesto que su discurso pasa a ser el discurso autorizado, o más propiamente el que tiene autoridad». 
los derechos o sobre los derechos, un discurso que se pretende técnico: «La Revolución Francesa - escribe EGE - ha aportado a la historia de la cultura occidental en el terreno del lenguaje jurídico algo mucho más sustancial que un repertorio léxico determinado, que haya de enumerar analíticamente; ha aportado un discurso enteramente nuevo para explicar las relaciones entre los hombres y su organización social y política como materia de derecho, discurso que expresa un sistema conceptual original... que ha cortado como un tajo la tradición histórica»?.

Ahora bien, ¿qué habrá que entender como «lengua técnica» o como «discurso técnico», tal vez artificial? ¿Se querrá afirmar que entre los diferentes discursos hay uno específicamente técnico o técnico-jurídico, el más apropiado para la ordenación de la sociedad que consiste en un orden artificial de derechos? No cabe buscar aquí excesivas novedades ya que EGE, acometiendo la tarea interminable de proponer pro-futuro un discurso integrador, recupera y reclama como nucleo de ese discurso el legado humanista, el legado implicado en la construcción idealista de un concepto Derecho cuyos ingredientes proceden más o menos indiscriminadamente del Derecho Romano, de la Escuela del Derecho Natural (en particular, de Locke, aunque también de Burke) y que a través de las grandes construcciones filosóficas de Kant y Hegel, desembocaría según EGE en la construcción jurídica, ya perfecccionada en el s. XIX, de la categoría de derecho subjetivo.

Un tercer aspecto de la exposición de EGE invita a una crítica más directa. Porque aquí ya no se propone una descripción o un análisis, sino que se trata de un pronóstico que no deja de ser una propuesta de lectura sobre la actualidad problemática de los derechos: una lectura que, obviamente, no puede de dejar de ser político-interpretativa. Así pues, escribe EGE: (si con la Gran Revolución)... «se abrió una época en la historia humana, que aún, puede decirse con el mayor rigor, continúa en su fase expansiva, tanto geográfica como respecto a la profundización de sus postulados básicos», las demás revoluciones del siglo XIX y XX («la revolución rusa, las revoluciones fascistas, las revoluciones integristas

9 «La lengua de los derechos, escribe a continuación EGE, debe explicarse, pues, no como simple aparición de nuevos términos... sino como la expresión de una nuevo discurso político que ofrece un nuevo modelo de relación entre los hombres» (de relaciones «jurídicas», estaríamos tentados de añadir, sin violencia de la posible intención del autor») (pág. 37) Queda oculto, sin embargo, en este párrafo y en el citado en el texto, el problema de la lengua y, sobre todo, no se subraya suficientemente que se trata también de la imposición (no simplemente, de una aportación) de un discurso sobre los derechos. $i$ Es una simple casualidad, o un acto de omisión deliberada por innecesaria, que en el libro de EGE no se cite, por ejemplo a Descartes como punto de partida - como irrupción también violenta- de ese nuevo discurso? ¿Puede pensarse en una lengua y una filosofía que de un modo más claro que el cartesiano prefigure la racionalidad de un sistema de derechos, construyendo precisamente el sujeto de los derechos, y que, por tanto, preste a la lengua las posibilidades de un discurso universal más sistemáticamente compacto? 
actuales», pág. 24) (simplemente) han pretendido recuperar ese espíritu utópico y de salvación que sólo entonces habría prendido en el hombre. Para EGE de lo que se trata es de «seguir el fascinante proceso de cómo esa «lengua de los derechos» que vimos aparecer en el momento mismo de la eclosión revolucionaria va a culminar en un tiempo muy rápido en la institución de todo un sistema jurídico completamente nuevo para regular las relaciones entre el poder y los ciudadanos, en un Derecho Público que apenas tiene que algo que ver con el Derecho Público del Antiguo Régimen y que tendrá un éxito espectacular en toda Europa, y posteriormente en el mundo entero, hasta hoy mismo».

«Esa extraodinaria creación — añade EGE — ni fue una ciega mutación histórica, según la explicación causalista del marxismo, ni fue tampoco una invención surgida de una vez en alguna menta excelsa o excepcionalmente lúcida. Fue, por el contrario, una construcción técnica intuida inicialmente más que diseñada en todos sus trazos, construcción llevada a cabo y casi ultimada en un proceso temporal no demasiado dilatado por grupos dirigentes y por juristas de muy distinta formación y procedencia».

En la actualidad, para EGE, una vez reconocidos y integrados los dos capítulos del Derecho Público revolucionario «que fueron dejados en dormición», esto es, el principio democrático como único principio de gobierno y el valor supralegal de los derechos fundamentales, «el conjunto de los principios del Derecho Público revolucionario se internacionaliza y pasa a los Tratados Internacionales». Aunque reconoce que, en la «última fase los principios de origen francés se conjugan con los procedentes del constitucionalismo anglosajón, los cuales, entre tanto, han superado en buena parte la vieja diferenciación entre règne de la loi y rule of law, tanto por la normalización de las regulaciones legislativas en el mundo anglosajón, lo que no ocurre hasta este siglo, como por el desarrollo en el mundo europeo de una nueva visión del juez, que supera resueltamente su papel subalterno como simple «boca que pronuncia las palabras de la Ley, y que admite, sin paliativos, al lado de la Ley, la operatividad de unos «principios generales del Derecho», con los que se supera el puro positivismo legalista.». Concluye EGE:

«Frente al viejo Corpus Iuris Civilis legado por la civilización romana a Occidente, comprensivo del Derecho Civil, para regular relaciones entre personas, he aquí un Corpus Iuris Civitatis que ha acertado a articular un sistena de relaciones entre los ciudadanos y los poderes públicos, un Derecho Público de la libertad, cuya irradiación ha sido aún más extensa y que fue forjado entre la violencia, la ensoñación y la razón en un momento concreto de la historia del pensamiento humano».

Para la configuración y la articulación de este nuevo sistema jurídico los juristas han debido «encontrar - dice EGE citando a Montesquieu- nuevas palabras o dar a las antiguas nuevas significaciones... Un nuevo universo conceptual, necesariamente servido por un universo léxico también nuevo ha ocupado así 
uno de los campos más delicados y apasionantes de la vida de los hombres, el de la articulación de la vida colectiva».

\section{LA AFIRMACIÓN AUTORITARIA DE LA LENGUA NACIONAL}

Hasta aquí, pues, la exposición que quisiera fiel a las tesis principales del ensayo de EGE. Ya hemos insinuado a lo largo de este comentario que EGE no presta gran atención al problema de la lengua en sí, al francés concretamente, aunque, no cabe duda de ello, en esta lengua se escribió el discurso de los derechos ${ }^{10}$. Para EGE, citando a R. Balibar, «la Revolución Francesa... es una revolución lingüística, la única revolución linguística hasta el presente en la historia del francés nacional».

Por tomar como ejemplo la propia lengua en la que más claramente se escribieron los derechos revolucionarios, es obvio que el francés nacional no ha existido siempre y su imposición como lengua no es ajena al surgimiento del Estado francés y a la revolución de su Derecho. Conviene recordar cómo y cuándo el francés se convirtió en la lengua de la Ley y del Estado, una lengua que se implanta por la necesidad del poder central de «inscribir» las leyes en la lengua nacional dominante, y cuya manifestación primera y más notoria, como es sabido, fue la Ordenanza de Villiers-Cotterêts (1539) ${ }^{11}$, dictada un siglo antes del Discurso del Método cartesiano. Conviene también recordar que éste fue el gran momento del triunfo de la estatalizacón monárquica, el acontecimiento que marcó el progreso masivo de una lengua francesa impuesta a las provincias como medio administrativo y jurídico, pues la imposición de una lengua de Estado tiene una

10 Se refiere EGE a la obra de Balibar, a los estudios de J. Guilhaumou, especialmente «la langue politique et la Revolution française. De l'evenement à la raison linguistique» (1989) y a otros importantes autores. Pero no deja de sorprender que junto al gran historiador francés Brunot, (Histoire de la Langue française (1905) monumento insoslayable, aunque ya viejo, no se refiera al libro de Marcel Cohen, «Historia de una lengua. El francés» (1947). Una comparación entre ambos sugiere de inmediato diferencias espectaculares, que por supuesto no se reducen al ámbito de la ideología política. Ninguna interpretación de la historia, ni siquiera la de la lengua, puede ser neutra, ni filosófica, ni políticamente. Habría que reseñar, por tanto, que en la obra de Cohen se encontrarían mucho más subrayadas las apuestas político-económicas, la relación con la historia de las técnicas en estos combates por la apropiación o la imposición de una lengua» (véase, Derrida, J., «La filosofía en su lengua nacional», Paidos, Pensamiento contemporáneo, Barcelona, 1995, pág. 37).

11 La ordenanza Villiers-Cotterêts (arts. 110 y 111) decía en uno de sus párrafos:

«...Y con el fin de que no haya motivo de duda sobre la inteligencia de las antedichas resoluciones queremos y ordenamos que estén hechas y escritas tan claramente que no haya ni pueda haber ninguna ambigüedad o incertidumbre ni lugar a pedir interpretación... queremos de ahora en adelante que todas las resoluciones, junto con los demás procedimientos, ya sean de nuestros tribunales soberanos y otros subalternos e inferiores, ya sean de registros, interrogatorios, contratos, comisiones, fallos, testamentos y cualesquiera otros actos y decisiones de justicia, o que de ella dependan, se pronuncien, registren y libren a las partes en lengua materna francesa y no de otro modo». 
evidente finalidad de conquista y de dominación administrativa del territorio, y sobre todo, la apertura de una ruta a la filosofía y al derecho ${ }^{12}$.

No cabe duda, pues, de que la proclamación de los derechos y el individualismo que constituye el subsuelo profundo del Estado de Derecho, es herencia de la Revolución, pero no cabe minusvalorar el hecho de que el avance revolucionario encontrara en el Antiguo régimen un terreno favorable a su desarrollo. Como es sabido, ya en el s. XVII se había formado una verdadera doctrina de los derechos del hombre y a su vez, ésta, se había formado a partir de los preceptos evangélicos, de las enseñanzas de la Iglesia y de la aportación de los legistas, esto es, la idea de que el hombre posee derechos los cuales deben traducirse en un estatuto jurídico garantizado por la autoridad pública (es decir, no tanto de un estatuto de ciudadanía como de un estatuto de libertad) que se habría consagrado a través del reconocimiento de un derecho a libertad personal y a la seguridad que justifica el fin de la servidumbre y el límite del poder monárquico ${ }^{13}$.

Constituye por ello una obviedad recordar que la «Declaración de Derechos», como por lo demás, cualquier otra Declaración posible donde se estipulen o prescriban derechos, sólo pudo hacerse desde la libertad que ya antes se haya conquistado (que no es, simplemente, el reconocimiento de un cierto derecho a declararlo, sino la declaración de unos derechos ciertamente conquistados). Como su nombre indica, el tono performativo de la Declaración de los Derechos presupone que tales derechos se poseen ya. El origen del ius publicum, pues, se encuentra ya prefigurado con el nacimiento de los Estados modernos y éstos a su vez suponen la imposición de una lengua, es decir, la prescripción autoritaria, aunque no siempre por medio de la Ley, de una lengua, como requisito indispensable para poder abonar el espacio de los derechos y de la seguridad jurídica. Desde este enfoque, la Revolución Francesa no sería el primer episodio, el primer acontecimiento, si queremos exprerarlo así, en la implantación o en el recorrido de una lengua de los derechos sino que éste vendría dado por la imposición de una lengua nacional (del Estado), en sí mismo un acto irruptivo de violencia en la instauración de un nuevo orden ${ }^{14}$. En cierto sentido, y por ello, la Revolución no

12 Derrida J. Ob. Cit. pág 42 y ss.

13 Vide, B. Barret-Kriegel, L'Etat et les esclaves, Paris, 1979.

14 Claro está que la rotundidad de la afirmación hay que matizarla en cada caso, pues no siempre la afirmación de la lengua nacional acompaña el nacimiento del Estado. Otras veces la precede pero siempre se involucra con la conformación de la comunidad jurídica y presupone, en una fase que no ha dejado de ser sino violenta, la erradicación de otras lenguas. Vide. I Simpósio Internacional de línguas europeas e lexilación. Santiago de Compostela. Octubre, 1992 (Comisión das Comunidades europeas), especialmente, Leachlain $\mathrm{O}^{\prime}$ Cathain, «O marco lexislativo en Irlanda», págs. 85 y ss., donde se expone cómo desde 1366 la Administración inglesa prohibe el irlandés en los dominios legal, político y social, y ya en los siglos XVII y XVIII se convierte el inglés en lengua de prestigio y de uso exclusivo en la Universidad y la política, y Claudio Magabosco, «Itália: minorias linguísticas ou minorias étnicas? págs. 28,29 y ss. Cavour declaraba en 1860: «ya tenemos a Italia, ahora tenemos que hacer los italianos» y desde su punto de vista no le faltaba razón pues por estas fechas apenas un $2 \%$ de la población hablaba «correctamente» el italiano. Nacida de un movimiento 
impuso una lengua - la francesa- (en la que por cierto se escribió con posterioridad, como recordó elegantemente Mirkine-Guetzevch, la Ciencia Política de los siglos XVIII y XIX) sino, en primer lugar, la Revolución trató de imponer un discurso y un método desde los que pensar los derechos: trató de imponer una Declaración con carácter universal, una lengua que buscaba una propia trascendencia como lengua nacional: una forma de imperialismo, se diría más tarde.

\section{LAS DIFICULTADES DE ESTABLECER UNA «LENGUA TÉCNICA»}

La Gran Revolución no fue, pues, el momento constitutivo del nuevo discurso, sino su momento impositivo, y por lo que se refiere a la lengua, una vuelta de tuerca en una espiral ciertamente represiva ${ }^{15}$. Es verdad que la Revolución, como momento constituyente, irradió con la fuerza performativa de todo momento fundador e impuso no sólo un derecho sino una fuerza interpretativa y, porqué no decirlo, una nueva y potentísima censura frente a todo aquello que no se aviniera con el ideal racionalista y emancipador. Pero retengamos también otro hecho que tiene que ver con ese afán de imponer una lengua y que se presenta como una las razones justificativas, a saber, el proyecto propiamente filosófico o científico de reducir la equivocidad del lenguaje, la pretensión, en fin, de garantizar la traducibilidad de éste y de presentar simultáneamente un discurso universal con valor jurídico, administrativo, policial y, por tanto, político y filosófico ${ }^{16}$. En la exposición de EGE, esa necesidad de un discurso transparente, aceptable en todas las lenguas, no como un discurso jurídico-concreto sino como un Discurso del Derecho, se trata de articular, como hemos visto muy de pasada, con uná referencia a la herencia del pensamiento humanista clásico; curiosamente, EGE no cita una sola vez a Descartes y sin embargo, ¿cómo pasar por alto la contribución decisiva de Descartes a la formulación de ese discurso sobre una lengua universal cuyas resonancias llegan hasta nosotros y sigue alimentando todo tipo de pro-

político, el Risorgimento, que se realizó mediante la anexión progresiva de los diversos estados de la península por el Reino de Cerdeña, regido por la dinastía de Savoia, Italia vivió mucho tiempo la necesidad de afirmar su unidad linguística. En esto, la visión de Cavour era compartida completamente por Mazzino y por Garibaldi.

15 Como señalé en una nota anterior, la fase culminante de la Revolución acentuó la intolerancia linguística y aunque ésta no tuviera consecuencias prácticas, sin estos datos no se entendería el papel de la escuela republicana en los siglos XIX y XX. El Decreto del 2 Thermidor prohibía, por ejemplo, en todo acto, incluso en los de carácter privado todo otro idioma que no fuera el francés. El XVI Pradial del año II, Grégoire presenta a la Convención su Informe sobre la necesidad y los medios de eliminar los «patois» y universalizar el uso de la lengua francesa.

16 En el caso del francés, la aludida ordenanza Villiers-Cotterêt lo señala con toda claridad: puesto que se presume que nadie ignora la ley, también «es preciso que la lectura o la inteligencia del texto legal se haga a través de un medio linguístico purificado de todo equívoco, a través de una lengua que no divida o no se disperse en malentendidos» (vide J. D. ob. cit. pág. 42). 
puestas? Descartes representa bastante bien esa estela estático-monárquica a que nos hemos referido y que va en el sentido del poder y del fortalecimiento de la instalación del derecho francés. También para Descartes lo importante no es la lengua en sí, lo que podríamos llamar la lengua materna o nacional, (aunque, como hemos visto, escribe en francés su «Discurso», para poder ser comprendido por todos), ya que la lengua así entendida pertenece a un plano secundario e inferior, sino el orden de las razones que no pueden sino reclamar la existencia de una lengua universal: al reclamar una filosofía universal ${ }^{17}$, reclama también Descartes una lengua universal, una torre de Babel terminada, donde tal «mathesis universalis», cuyo modelo es la matemática ${ }^{18}$, da por sentado que la investigación no se deja detener por la equivocidad del lenguaje, pues para formalizar (empleando, por ejemplo, un lenguaje técnico), dice Descartes, «hay que vencer todas las oscuridades, la ambigüedades, las equivocidades de la lengua natural» ${ }^{19}$. Encontramos en Descartes, en definitiva, un ejemplo muy relevante del intento filosófico de buscar ese lenguaje universal, esa esencia originaria del idioma (cuyo uso histórico en formas de lenguas maternas o nacionales es una degeneración, una irregularidad hasta cierto punto inútil), pero también, al menos, el reconocimiento de la dificultad para dar con él, sobre todo para poder implantarlo.

Al menos, esta dificultad que señala el filósofo francés debería hacernos

17 En las «regulae» (1629) Descartes declaraba: «...sostengo que esta lengua es posible, y que puede hallarse la ciencia de la que depende, por medio de la cual los campesinos podrían juzgar mejor acerca de la verdad de las cosas de lo que hacen ahora los filósofos. Pero no esperéis verla jamás en uso; esto presupone grandes cambios en el orden de las cosas, y sería preciso que el mundo, todo él, no fuese sino un paraíso terrenal, lo que no puede proponerse más que en el país de las novelas». En las «Reglas para la dirección del espíritu» (1989) habla de reglas, preceptos técnicos en la búsqueda de la verdad (reglas: la palabra expresa bien lo que ha lugar a hacer, de forma regular, recurrente, repetitiva y por tanto formalizable para conducir y conducirse bien en la vía del conocimiento). La lengua, para Descartes, permanece en un plano secundario. Pide no contentarse con leer: hace falta también meditar por orden. Este orden no es el de la lectura, es el de las razones u orden esencial. Es claro, pues, que Descartes no abogaba por una lengua materna sino que abogaba por poner la lengua al servicio de la razón natural o de la luz natural.

18 De la misma forma, dice Descartes, que hay un orden naturalmente establecido entre los números; y como pueden aprenderse en un día a nombrar todos los números hasta el infinito, y a escribirlos en una lengua desconocida, constituyendo en todo caso una infinidad de palabras diferentes, se podría hacer lo mismo con todas las demás palabras necesarias para expresar el resto de cosas que se hallan en el espíritu de los hombres. Si esto se encontrara no dudo en absoluto que esta lengua se extendería rápidamente por el mundo...» (oevres y lettres, IV, 94).

19 Descartes sostiene, en efecto, que tal lengua universal es posible ...«y que puede hallarse la ciencia de la que depende... pero no espereis verla jamás en uso; esto presupone grandes cambios en el orden de las cosas y sería preciso que el mundo, todo él, no fuese sino un paraíso terrenal, lo que no puede proponerse más que en el país de las novelas». (Reglas para la dirección del espíritu, Madrid, Alianza, 1989). 
$\operatorname{meditar}^{20}$ : para Descartes, por un lado, las palabras de ese lenguaje universal, que cree necesario y posible ${ }^{21}$, no designarían sonidos o sílabas sino conceptos, unidades semánticas, el principio mismo del orden. Pero, por otro lado, aún sosteniendo que esa lengua es posible (necesaria como discurso filosófico), no espera verla nunca en uso ya que «eso presupone grandes cambios en el orden de las cosas, y sería necesario que el mundo, todo él, no fuera sino un paraíso terrenal, lo que sólo puede proponerse en el país de las novelas». Esta advertencia de Descartes, que sitúa el problema de las lenguas nacionales en un terreno de nadie, a mitad de camino entre la universalidad filosófica y la universalidad de la lengua natural, no ha sido seguramenre advertida en el discurso más lineal de EGE, pero sabemos que, pese a los intentos de éste y de los que proponen sin más una necesidad de una lengua de los derechos, sin plantearse la problematicidad en sí de las lenguas, abonan un camino puramente idealista que no puede captar lo que de estrictamente político y jurídico plantean éstas con urgencia.

\section{LA TERCERA MUTACIÓN}

Volviendo, pues, al tema principal de estos comentarios al libro de EGE y al problema de la construcción del derecho europeo, al problema de las lenguas desde las que precisamente ha de construirse, creo que el discurso de EGE no está completo sino que omite dos datos esenciales: de un lado, el Estado que está en el origen de la formación del derecho público y de su lengua oficial unida a aquél (y que lejos de desaparecer, renueva su presencia en esta nueva etapa post-Maastricht) y, de otro, la realidad de una nueva revolución, esta vez también tecnológica que requiere como siempre su lenguaje y su discurso. Esquematizando en exceso, si aludo a estos dos referentes principales es porque, en mi opinión, señalizan las intrincadas e inseparables relaciones que vinculan a los derechos y sus lenguas: la formación del Estado con su derecho escrito ya en una lengua nacional, de una parte, y las Declaraciones liberales que albergan en su interior la pretensión de ser

20 Como, por otro lado, también podría ser motivo de meditación la reflexión cartesiana sobre el sujeto del derecho, porque, ¿qué hay precisamente del sujeto de esa subjetividad y de ese derecho? También en esto parece inevitable el encuentro con Descartes, precisamente si el propósito de un discurso sobre los derechos (como el que EGE expone) no es simplemente el recorrido por una genealogía, un recorrido historicista, que trata de desvelar, por capas sucesivas, un contenido presuntamente esencial, (desde la filosofía de Occan, a la huella de la segunda escolástica española, pasando por Locke, Burke, etc.), es decir, de un recorrido que trata de explicar cómo se produce la objetivación del Derecho (la formulación de un derecho objetivo) precisamente mediante la delimitación de una noción de derecho subjetivo, construida esencialmente, como ya hemos señalado, sobre el derecho de propiedad.

21 Para Descartes, un orden inteligible (el que va por el camino o método recto y esencial) es asexuado (no precisa una lengua «materna») El cogito se refiere a un sujeto que no tiene ninguna marca sexual (ni linguística), puesto que es una res cogitans y no un cuerpo. La subjetividad del sujeto que se funda en el gesto cartesiano quedaría, para el cuerpo o la lengua, sexualmente indiferenciada. 
un discurso universal de los derechos, de otra. ¿Marcan estas dos referencias una dirección inexorable y habrá de mirar necesariamente hacia el horizonte de una reuniversalización en un nuevo nivel, el de la mundialización, que requiere para algunos un único y nuevo lenguaje, un lenguaje técnico limpio de todas las «impurezas» de las lenguas naturales o nacionales?

Tal vez sería éste un efecto al que podrían contribuir las revoluciones tecnológicas de este fin de siglo. Pero no haría falta siquiera detenerse en las características de esta tercera mutación, para describir otro tipo de impactos que la revolución telemática o tecno-mediática está produciendo en esas dos realidades, el Estado y el discurso técnico-universal de los derechos, a las que hemos hecho referencia: una nueva «crispación» se esparce con innumerables efectos que sería arriesgado describir siquiera en sus grandes líneas, pero que, con todo, cabría agrupar en dos grandes direcciones: por una parte, un despertar de las minorías lingüísticas $y$, por otra, un combate contra la monopolización de la lengua tecnocientífica que se está produciendo de la mano de las fuerzas tecno-linguísticas que dominan el mundo del comercio, la industria de las telecomunicaciones, la informatización, los soportes lógicos, los bancos de datos, etc. El despertar de las minorías linguísticas, la emergencia poderosa de estas culturas minoritarias tiene más de una relación con el papel de las redes, los instrumentos, recursos y oportunidades de la intercomunicación. Hasta ahora, ha predominado una idea «cultural» de las minorías lingüísticas que al no rebasar el orden de la memoria cultural no amenazaba en nada la unidad linguística del Estado-nación. Las exigencias de mayor respeto hacia las diferentes minorías culturales se han dejado sentir en los numerosos textos que, en el ámbito europeo, han reafirmado los derechos llamados culturales ${ }^{22}$. Pero la revolución mediática puede estar llevando el problema un paso más allá, porque se puede tratar desde ahora no sólo de reivindicar los derechos de los colectivos culturales minoritarios o de las minorías nacionales, siempre problemáticos en la delimitación de su titular, sino de la

22 El Consejo de Europa estableció un modelo propio de reconocimiento y de protección de los derechos del Hombre y de las libertades fundamentales, en la línea de la Declaración Universal, ya en la Convención de Roma de 1950 y más directamente en la Convención Cultural Europea de 1954. En los últimos años, el Consejo de Europa ha promovido líneas de trabajo más específicas como la eleboración de una Carta Europea de las Lenguas Regionales Minoritarias o la recomendación 1.134 (1990) de la Asamblea parlamentaria sobre protección de los derechos de las minorías. La Conferencia sobre la Seguridad y Cooperación en Europa (CSCE), por su parte, incluyó en el Acta Final de Helsinki (1975) el principio de desarrollo político, económico, social y cultural (VIII); en la Carta de París, la CSCE reafirma especialmente la necesidad de protección de la identidad étnica, cultural, linguística y religiosa de las minorías sin discriminación. Sin embargo, los Tratados de la Comunidad Europea no incluyen directamente referencia alguna a la cultura ni a los derechos culturales o linguísticos que han de ser protegidos; sólo de modo indirecto, se reconocen algunos derechos en la medida en que afecten o queden afectados por la construcción del mercado interior y la libre circulación de bienes, personas y mercancías. Vide. Josep Gifreu, Drets culturals i espais de comunicació, en Drets lingüistics i drets culturals a les regions D'Europa. Actes del Simposi Internacional, Generalitat de Catalunya, Barcelona, 1995. 
reinvindicación de un nuevo concepto de ciudadanía que, al desbordar el marco estatal, sitúa el problema de la lengua propia (el derecho a la lengua propia) como algo inseparable del Derecho, y en un orden del que casi se podría decir que el derecho a la lengua precede a los demás derechos. ¿Cabe este discurso en el concepto de ciudadanía europea que surgió en Maastricht?

No es posible renunciar a la universalidad formal del valor de los derechos, porque ello es garantía de seguridad y de aplicabilidad: es la condición también para luchar contra toda arbitrariedad; pero hemos de reconocer que esto no será ya posible sin partir de la pluralidad de las lenguas y de un concepto de derecho que no puede afirmarse sobre la base de una imposición de un momento constituyente, sino como el resultado no programable de un proceso abierto a los otros, es decir, a otras lenguas. Como un derecho que, en definitiva, tendrá que dar la palabra a esas mismas lenguas en primer lugar, no para reafirmar la existencia de una pluralidad de proyectos nacionales, sino para abrir el camino a un nuevo concepto de ciudadanía. 